\title{
Single Parenting and Its Effects on the Psychosocial Development of Children in Swaziland
}

\author{
Mabuza, N \\ Department of Educational foundations, University of Swaziland \\ futhikunenemabuza@gmail.com \\ Thwala, SK \\ Department of Educational foundations, University of Swaziland \\ sskthwala@uniswa.sz \\ Okeke, $\mathrm{ClO}$ \\ Faculty of Education, University of Fort Hare, RSA \\ cokeke@ufh.ac.za
}

Doi:10.5901/mjss.2014.v5n23p2252

\begin{abstract}
The study used an exploratory design to examine how children who are raised by single parents develop cognitively, socially and emotionally. It employed a questionnaire instrument distributed to a purposive sample of N=397, FGD N=24 respondents and individual interviews $N=4$ respondents. Descriptive statistics were used to describe the demographic characteristics of the respondents. Chi square analysis helped to establish the relationship among demographic variables and major components among the items. Qualitative data were examined by dividing the data into segments that reflected themes and a development of a theory in the form of verbal statement or themes were offered to explain what happened in the phenomenon. Quantitative and qualitative research findings revealed that single parenting has negative effects on the psychosocial development of children. The study recommends that parents and teachers in Swaziland must be provided with information pertaining to the psychosocial development of the children. There is also the need for specific policy that compels all parents to take responsibility of their children.
\end{abstract}

Keywords: Swaziland, children, parenting style, single parenting, psychological development, consequences

\section{Introduction}

The family is an important unit in the society. It is the first socializing agent the child interacts with and it has great influence on the child's physical, mental, moral and social development (Roska \& Potter, 2011; Cavanagh \& Fomby, 2012). The family's most outstanding responsibility is to train and bring up the child in the norms and values of the society. Hence, Davis (2011) observed that the foundation of what the person becomes in the society is laid in the home at the initial stage of life. However, there are certain circumstances in families which require that the parenting role be left in the hands of single parents. These include divorce, denied paternity, rape, separation of various kinds, and deaths of one spouse (Nyakutse, 2006; Thwala, 2011; Falana, Bada \& Ayodele, 2012). The society continues to grapple with the breaking down of family structures which adversely affect the development of children in particular. In Swaziland divorce, poverty, urban migration, HIV and AIDS pandemics; all of these are contributing to the breakdown of the Swazi family. With regard to the rapidly growing population of single parents and its implications on the children raised in such families, an in-depth exploration of the phenomena was therefore necessary. The main research question that guided the study was thus: what were the effects of single parenting on the psychosocial development of children in Swaziland? The main objectives of the study therefore were to: i) examine the cognitive, social and emotional development of children who are raised by single parents; and ii) determine the role of the parent in the psychosocial development and well-being of the child. 


\section{Theoretical Framework}

Both Erikson's (1902-1994) theory of development and Bandura's (1977) social learning theory were adopted in the study. Erikson's theory was chosen for the study because many developmental theories only cover up to adulthood, whereas Erikson's encompasses development throughout the entire lifespan, dividing the stages of adulthood into the experiences of young adults, middle aged adults and older adults (Heffner, 2004). Development according to Naug (2000) is an ongoing process and failure to meet psychosocial needs of a child at an early stage will result in personality disorder and unhappiness in future. Erikson's theory integrates personal, emotional and social development rather than focusing on one aspect of human growth, and thus it is called 'psychosocial development. In Erikson's theory eight stages of development unfold as people go through their life span and each stage consists of a unique development task that confronts individuals with a crisis that must be resolved (Bosma \& Kunnen, 2001). Erikson emphasizes that this crisis is not a catastrophe but a turning point of increased vulnerability and enhanced potential. The more successful an individual resolves the crisis; the healthier development will be (Santrock, 2006; O'Connor \& Scott, 2007). Erikson's theory gives a clear guideline for understanding human behavior thus helping the researchers to investigate how single parenting affects the psychosocial development of children in Swaziland.

On the other hand, Bandura (1977), and Good and Brophy (1995) emphasize that cognitive development has important links with the environment and behavior. Bandura (1977) proposes that people cognitively represent the behavior of others and then sometimes adopt this behavior themselves. For example; a young boy might observe his father's aggressive outburst and hostile interchanges with people, when observed with his peers, the young boy's style of interaction is highly aggressive, showing the same characteristics as his father's behavior. Social learning theorists (O'Connor \& Scott, 2007; Moime, 2009; Ajidahun, 2011; Falana et al. 2012) stress that people acquire a guide range of such behavior, thoughts and feelings through fit or incompatibility between the child and the environment. Bandura's social learning theory is suitable for our study because it views behaviour as a learned phenomenon. It assumes that children learn behaviour when they see their parents or other significant others behaving in a particular manner. So if children see their parents acting irresponsibly, they too may decide to act in like manner, and if the parents do not have good relationships with the children, the children too may not have good relationships with the people they stay with or the people they interact with even outside of the home (Scott \& Lilja, 2010; Fletcher \& Stenberg, 2004; Mwamwenda, 2004.

\subsection{Single parenting and effect on children}

Numerous studies suggest that single parenting have effects on the child. Harrison-Hale, McLoyd and Smedley (2004) emphasize that single parents often have less time for general supervision and daily monitoring of their children. Parents and children from single parenting households may also communicate less about the children's needs than children in traditional two parent families (Copeland, 2010; O'Connor \& Scott, 2007; Roska \& Potter, 2011; Thwala, 2011 Cavanagh \& Fomby, 2012). Studies on single parent families link father or mother absent households as a causative factor in numerous social problems (Pharaoh, 2004; Symeon 2007; Waldfogel, 2010; Davis, 2011; Cavanagh \& Fomby, 2012). The overall relationship between a parent and his or her child is likely to affect the psychosocial well-being of the child. Symeon (2007) notes that children of single parents are more likely to display risky behaviors: smoking, drinking, delinquency, violence, unsafe sexual activity and suicide attempts. If a child is unhappy, he/she is more likely to smoke or drink; children need to feel secure and that may be difficult in single parenting households according to Copland (2010).

A study by Salami and Alawode (2000) found that a child from homes where the father and the mother are present will be taken care of and socialized in the best way possible. This is due to the fact that the process of socialization depends on both parents playing complementary roles in bringing up the child. Such a child is likely to achieve selfactualization later in life (Davidson, 2000; Santrock, 2006). Children from single parent homes are likely to suffer deprivation and denial of some rights and opportunities (Crosnoe, 2007). Moime's (2009) study revealed that failure on part of parent and teachers to meet the psychological needs of the child at a certain stage in his/her development may result in personality disorders, which can become a potential danger and a source of unhappiness to the individual. Rising rates of divorce and non-marital fertility along with declining rates of marriage and re-marriage have created diversity in the structure of families (Peplau \& Beals, 2004; Copeland, 2010; Scott \& Lilja, 2010; Azuka-Obieke, 2013). Such diversity has been implicated in the psychosocial development of the children (Azuka-Obieke, 2013; Kelly, 2003; Waldfogel, 2010). Corn's and Reab's (2007) study found the likelihood of more substance abuse among children of single mothers than among children of two biological parents. According to Scott and Lilja (2010) a growing number of children are living in non-traditional families, mainly as a consequence of rising divorce rates. In order for children to develop 
psychosocially they should have a good and solid background environment which will help them develop a positive selfimage and self-identity.

\subsection{Parental impact in the psychosocial development and well-being of children}

Studies show that parents have a responsibility to raise their children and are equally held responsible for their children's health, safety and socialization until the time that they can live without adult supervision (Naug, 2000; Kelly, 2003; Moime, 2009). However, studies have shown that parents are often pre-occupied with the stress and strain of their own lives, especially parents who are struggling to deal with their own identities and problems (Moime, 2009). This may be the case with single parents. Studies indicate that single parents may be dealing with the issue of raising children on their own as well as issues with their own identities (Roska \& Potter, 2011). Parenting requires interpersonal skills and most parents learn parenting practices from their own parents (Naug, 2000; Straus, 2001; Steinberg \& Silk, 2002). Stevenson and Zusho (2002) emphasize that parents do not want their children to be frustrated in trying to discover the best way to accomplish life.

Parents anticipate and visualize the kind of individual they want their child to become. In a general sense, there are traits that they admire as well as a value system they wish to instill (Copeland, 2010; Crosnoe, 2007; Scott \& Lilja, 2010). Children identify with and model much of their behavior and attitudes after their parents and caretakers. This means that if parents desire children who are moving towards self-actualization, then the parents themselves must strive for greater self-actualization (Guest, 2007; Azuka-Obieke, 2013). However, divorce and separation of various kinds or death of one spouse may leave the roles in the hands of a single parent, and whatever vulnerability persist can affect a youngster's self-perception, self-esteem, and relationships with others (Scott \& Lilja, 2010). More so, Simons-Morton (2001) and Amato, Kane and James (2011) note that good parenting takes time and effort to materialize. Parents who do not spend enough time with their children may not know what is happening to their children as they develop (Kelly, 2003). Sacrifice on the part of the parent is essential, whereby the parent will spare some time to take interest in children's studies.

\section{Methodology}

Exploratory research design and mixed methods approach (Babbie \& Mouton, 2001; Schumacher \& Macmillan, 2006; Creswell, 2014) was followed to gain in-depth information about the respondents' views and experiences, which eventually helped us to identify themes and explain the meaning of the social phenomena (Leedy \& Ormrod, 2010). The study adopted a stratified purposive sampling technique to select the schools, children and parents. Four schools were selected from each of the regions and a total of 397 children (199 from Shiselweni and 198 from Manzini) took part in the study. Four (4) single parents were purposefully selected to determine the role they played in raising their children and also ascertain the challenges they faced as single parents. This sample was selected with the help of the class teachers and guidance teachers who knew the parents since they were expected to consistently communicate with each other regarding the children's performance at school. The questionnaire was divided into section A, which provided biographic information, and Section B, which both the closed-ended questions and open-ended questions reflected on the psychosocial well-being of the child participants. Four (4) focus group interviews were conducted with children from eight schools. Six (6) children participated in each group discussion, which lasted for 1-2 hours in each case. The children were of mixed gender and these were the same children who took part in the questionnaire exercise. The questionnaire instrument was validated by a panel of experts in the Faculty of Education in one Southern African Universities while all three data collection instruments were then pilot-test using three (3) children who were raised by single parents and one (1) single parent who were not selected for the actual study.

Quantitative data was analysed using the Statistical Package for Social Sciences (SPSS), version 20. Quantitative data analysis involved simple descriptive statistics and the results were presented in tables. Chi-square values were used to show the statistical significance between the variables. A $p$-value $(p<0.05)$ represented a statistical significant relationship. Qualitative data from focus groups and individual interviews was analysed by scrutinizing data for commonalities that formed themes, which were then used to describe what was established. Development of a theory in the form of verbal statement was offered to explain the effects of single parenting on the psychosocial development of the child.

\subsection{Ethical considerations}

When conducting this study, the researchers asked each respondent to sign an informed consent declaring willingness to 
take part in the study, making sure that any participation in the study is strictly voluntary. The researchers also made sure that participant's right to privacy was respected (Neumann, 2006). The researchers also agreed that under no circumstances should data be presented in a manner injurious to the participants in the study. All participants in the study had the right to withdraw from the study or to request that data collected about them not to be used.

\section{Findings}

\subsection{Family Background and parental assistance}

Findings of the study suggest that most of the children lived with their grandparents (49.3\%), and a few lived with either their aunt $(12.6 \%)$ or uncle $(10.2 \%)$. There were proportionately more females (53.7\%) than males children (41.5 \%) living with their grandparents. Uncles supported proportionately fewer children (10.2\%) than aunts (12.6\%). There were slightly more male children living with uncles (14.8\%) than those living with aunts (14.1\%). Amongst female children, there seemed to be a preference for aunts (11.8\%) than uncles (7.7\%). The demographic information provided by the respondents revealed that male parents preferred to stay with male children, while female parents preferred to stay with female children, this was also true with the grandparents and aunts. Data also revealed that the differences between males and females were marginal in terms of their response to being assisted by their parents with homework. Both males and females were likely to be assisted by their parents in their school work with having $61.7 \%$ females and $62.5 \%$ males, agree to being assisted by their parents with school work.

\subsubsection{Children's age and its influence on parental assistance}

There was statistically significant differences in the perceptions of children of different ages $p<0.05$ with regards to parental assistance with school work $p=0.03$. Children aged between 12 and 15 years $72.5 \%$ were highly likely to have parental assistance in their school work, whereas the children between 19-24 years were less likely to get any parental assistance with school work with a negatively correlated increase in child's age as shown in Table 1.

Table 1: Age group and parental assistance

\begin{tabular}{|c|c|c|c|c|c|}
\hline & & & \multicolumn{2}{|c|}{ Person assisting } & \multirow{2}{*}{ Total } \\
\hline & & & Disagree & Agree & \\
\hline \multirow{6}{*}{ Age Group } & \multirow{2}{*}{$12-15$} & Count & 25 & 66 & 91 \\
\hline & & $\%$ within age group & $27.5 \%$ & $72.5 \%$ & $100.0 \%$ \\
\hline & \multirow{2}{*}{$16-18$} & Count & 52 & 76 & 128 \\
\hline & & $\%$ within age group & $40.6 \%$ & $59.4 \%$ & $100.0 \%$ \\
\hline & \multirow{2}{*}{$19-24$} & Count & 32 & 36 & 68 \\
\hline & & $\%$ within age group & $47.1 \%$ & $52.9 \%$ & $100.0 \%$ \\
\hline \multirow{2}{*}{ Total } & & Count & 109 & 178 & 287 \\
\hline & & $\%$ within age group & $38.0 \%$ & $62.0 \%$ & $100.0 \%$ \\
\hline Chi-Square, p-value & $7.025^{*}$ & 0.030 & & & \\
\hline
\end{tabular}

*significant at $p<0.05$

\subsubsection{Influence of siblings on parental assistance}

There was no significant difference with regards to number of siblings the children have and the parental assistance they get with their school work. However, both parents and children appeared to be challenged in cases where the siblings were more than 6 . It would appear that single parents were faced with challenges assisting children with school matters where there were more than 6 siblings. The difference is minimal with children with no siblings and those with 1-6 siblings. 
Table 2: Number of siblings and their influence on parental assistance

\begin{tabular}{|c|c|c|c|c|c|}
\hline & & & Person & ting & Total \\
\hline & & & Disagree & Agree & Iotal \\
\hline & 0 & Count & 1 & 2 & 3 \\
\hline & 0 & $\%$ within siblings & $33.3 \%$ & $66.7 \%$ & $100.0 \%$ \\
\hline & & Count & 27 & 46 & 73 \\
\hline & $1-2$ & $\%$ within siblings & $37.0 \%$ & $63.0 \%$ & $100.0 \%$ \\
\hline & & Count & 35 & 57 & 92 \\
\hline Number of siblings & $3-4$ & $\%$ within siblings & $38.0 \%$ & $62.0 \%$ & $100.0 \%$ \\
\hline & & Count & 18 & 34 & 52 \\
\hline & $5-6$ & $\%$ within siblings & $34.6 \%$ & $65.4 \%$ & $100.0 \%$ \\
\hline & & Count & 21 & 24 & 45 \\
\hline & $>6$ & $\%$ within siblings & $46.7 \%$ & $53.3 \%$ & $100.0 \%$ \\
\hline & & Count & 102 & 163 & 265 \\
\hline Total & & $\%$ within siblings & $38.5 \%$ & $61.5 \%$ & $100.0 \%$ \\
\hline Chi-Square, p-value & 1.712 & 0.789 & & & \\
\hline
\end{tabular}

\subsection{Effects of single parenting: Children viewpoints}

Participants' responses suggested that there were negative effects of not having the other parent. Those who reported that it affected them negatively were concerned with payments of school fees, having proper school uniforms, assistance and support they got from their parents with their school work. One child participant notes in the following sentences: "I feel unhappy, she cannot afford to pay fees on time (for the four children) we are often sent home to ask for money while the rest are learning, and at the end of the year I fail and repeat grade...". Findings also suggest that children from a single parent home classes: "I don't have school uniform and sometimes at school they send me home for not having proper school uniform and for not paying school uniform".

Findings suggest that children may be affected by the relationship with the parent and by the level of education of the parent. According to this 16 year old female learner in Form 2 living with a paternal uncle bluntly put it: "My uncle only wants to pay fees for his children..." Regarding the effect of the level of parental education, one child participant declared "Sometimes I have no one to help me with school work because my mother did not have any good job and had no one to assist her at home. This affects me emotionally...when we are given an assignment that requires assistance from my parent." This was echoed by a 20 year old female in Form 5 who lamented that: "I have to walk to school and don't have time to study as I am always tired, hence I sleep in class." This comment suggests that the children's experiences may also be influenced by the characteristics of the parent they live with.

Findings also show that children of single parents face a lot of frustration and faced stigmatization in some instances. This was the case with this participant when she said: "I am frustrated...not getting sufficient support from my parent." The findings of the study also show that children from single parent households experienced identity confusion and stigmatization. According to this learner "My dad passed away...sometimes my friends say I behave like I grew up without parents and I sometime feel like not coming to school and face them because I cannot change the way I am" 16 year old girl who lives with her civil servant typist mother.

Findings suggest that children were aware of some of the challenges that their parents had to grapple with. One of the boys living with the mother noted that "My mother is always stressed, sometimes shouts at me". Children in single parent households may assume the role of the other absent parent: "Father sometimes goes out and comes back late, so I have to do all the house chores and look after siblings..." 18 year old male in Form 5. The effects could be emotional and could entail the lack of basic needs such as school fees and uniforms according to this statement: "We sometimes go to bed without anything to eat..." Surprisingly, the children indicated that life would be better if they had both parents and they indicated that they wished to change the situation if they could, but unfortunately they could not: "If we had both parents we can live better and carry lunch box; have proper uniform or have a new house".

Results also indicate that some of the children equally regarded the situation as an opportunity for them to take up challenges for the better. Some children reported that they had used the negative situation at home to achieve positive results: "It helps me to be strong spirited and open minded..." One 17 year old boy suggested that: "Knowing you cannot have everything you want like other children make you ambitious and improve your future in every way you can." However they could not deny the challenges they faced as children growing up in single parent family set up despite their wish to remain positive: "It motivates me to do better and make my mother proud, however, I often get depressed, but I 
guess I am coping" Single parenting and living in a single parenting household may bring excessive pressures and immense stresses on both the children and their parents. This is, for instance, reflected in the comments of a motivated 14 year old girl who was in Form 3: "I have to work extra hard to impress my mother \& make her happy. If I fail, she will shout at me and may not talk to me for some time. Each time I ask about my father, my mother avoids the topic."

Findings equally suggest that children from single parent family wish for a family set up that had both parents: "I do wish I lived with both my parents". The children from single parent households reflected a general envy towards those children who had both parents and were able to afford most things". According to this 17 year old in Form 2, "I feel unhappy and anxious when other children eat from their lunch boxes in front of me, have their pocket money and wear proper uniform..." 17 year old boy in Form 2. "My father died: It does not affect me but sometimes I cry when I see someone walking with his/ her father" 12 year old girl. One 16 year old boy took it further and reflected that: "It hurts when other children talk about how daddy's going to take them to the movies, how daddy shouted at them in the morning". This was also echoed by another 18 year old female student: "I miss that fatherly love and guidance... every time I think about it, my eyes fill with tears". Children's comments also suggested curiosity and a longing for the one absent parent which may affect their relationship with the parent with whom they lived: "I know a little about him. He was a caring dad...I feel jealous especially when I see some children with their fathers. I prefer my dad to my mom" (16 year old girl living with grandmother).

\subsection{Parents' perspective on the effects of single parenting on children}

There was a consensus amongst the parents' participants that single parenting had negative effects on children. The four parents who took part in the study noted that they did not have enough time with their children and they could not attend all school meetings since they had to work excessively to bring food on the table. This created problems because the children needed them, in their daily lives. Their unavailability created space for powerful sources of influence such as friends, television, siblings, and drugs to come into play. One parent even blamed herself that her child dropped out of school due to pregnancy and when she tried to find out where it went wrong, she discovered that her daughter was influenced by her friends. Another parent admitted to have discovered very late that her son was a drug addict and she stated that it took her so long to discover this because she would arrive home late and leave early for work; she had no time with her children. This was because she was working odd hours and she desperately needed the job.

They responded by saying that single parenting frowned at in the Swazi society and as a result single parents especially the women, were discriminated. They were called names as 'imitalakanye' (having a baby before marriage), 'emabuya' (failures because they are divorced, and so raising children on their own). Interestingly enough, no names were given to the single fathers. Also the society would keep reminding single mothers about the father of the child even when the respondent wanted to accept the fact that they had separated with the father of the child and wanted to move on with life. The constant reminder about the father was ever there. The respondents also pointed out that if they were staying at their parental homes with their children, they could never be treated as adults even in front of their own children. This in turn would hurt the children and at times would cause the children to lose respect for their parents.

The main reasons for having more single parents as cited by the respondents were that nowadays there are so many break ups, divorce and separation and decline in moral standards. The participants also emphasized that in Swaziland, there was no law that compelled parents to be responsible parents. The respondents emphasized that rather than the Swazi government putting pressure on the irresponsible parents, the government had come up with free education and feeds the children through neighborhoods care points. At the care points, all the vulnerable children are given free food with the help of government, yet some of these children have parents who were working but they were just being irresponsible.

\section{FGD with Children}

Theme 1: Time constraint

Specifically, data from the FGD appear to suggest that lack of time with children posed a huge problem on the quality of attention those children received from their parents. The respondents indicated that they did not get enough time with their parents to discuss issues. They attributed this to the unavailability of the only parent who was ever busy trying to make ends meet and as a result could not have the time to show love or share quality time with the respondents. The lack of quality time with the parent, according to the discussants, then caused them to mistakes like engaging in "love affairs" that resulted in teenage pregnancies. 
Theme 2: Financial constraints

Most respondents indicated that their single parents were struggling to provide for their basic needs. The participants also indicated that it was painful to see other children buying good things at break or lunch time, whereas they could not even afford a candle light they could use when studying. This is how one of the children represented the scenario: "Immediately the bell rings for after school, I feel depressed because I have to think of the situation at home. I also have to think about money to buy the candle which I will use when doing my homework and when studying. This upsets me because if I don't do my homework, I know I will be in trouble with the teachers at school."

Discussions also revealed that children of single parent more likely to be chased out of school for lack of school fees and this really affected their academic performance. Other than that they also missed out when other children went for educational trips because their parents could not fund for such trips. One respondent had this to say: "Trips are seen as a luxury for some of us and we know it is not meant for us because we know our situation at home".

Theme 3: Children's emotions towards parents

Most male children who took part in the discussion indicated that they did not love their fathers (missing but alive fathers). Some even said they held grudges for the missing fathers because they were not responsible and had caused them and their mothers to suffer by depriving them of good life. The children indicated that even the welfare office could not rescue them; they voiced it out that involving a social worker was a waste of time because there was no way the parent could be forced to cater for the well-being of the child. One of the male participants said: "We would rather suffer for a short while rather than to force that person to give us his money. If the welfare officer forces him to pay for our needs, he would not be doing it at his own will. The respondents also voiced out their hurts caused by their missing fathers who inflict pain on their mothers. However, this inspired them to exert more effort in their school work to ensure that they made their mothers proud. A participant expressed his feelings in these words: 'I love my mother, she is my pillar of strength and I really do not want to disappoint her. I cannot imagine life without my mother, she is everything to me." Also another participant had this to say: "Despite the fact that our mother does not stay with us, I still maintain my love for her and I don't blame her for what she did. I have seen her suffer in the hands of my abusive father. The fact that she still cares for us yet she is in another relationship makes me proud and makes me to love her more".

Theme 4: Stigma and Discrimination

FGD data reveal that children of single parent household experienced discrimination. They were called names and sometimes reminded that they did not belong to certain families: "Akusiko kini lapha" (meaning that this is not your home). They were also reminded at times that they should find their mothers and tell them about their needs: "Unyoko akekho lapha" (meaning that your mother is not here). The discussants also indicated that they tell their mothers (married elsewhere) about this, the response they get is that of 'ngeke uhlale ekhaya lebantfu' (I cannot take you to where you do not belong'). This then created confusion and so much pain because even at grandmother's place (paternal) the child was constantly reminded that it was not his/her home. In most cases the father was not even there to console or support the child. The father was also married to a stepmother who also ill-treated and discriminated against the child.

Theme 5: Hope for the Future

It also emerged from the discussions that in the midst of the challenges the respondents were looking forward to a bright future; hence they were working extra hard at school to become self-sufficient and independent. The motivating factor being that they wanted to prove to the world including their irresponsible parents that they could be something even though they had dysfunctional backgrounds. Another motivating factor was the wish to please their only parents who sacrificed a lot to support them. The respondents had mixed feeling concerning marriage and raising their own children. Some felt that they wanted children, whereas others felt that children should wait. For those who said they wanted children, they made it clear that they would not wish to raise the children on their own, unless forced by circumstances. Concerning marriage, most participants noted that marriage was not an issue. Some said that they did not want to get married. One emphasized saying: "I don't wish to get married because people are not trustworthy these days".

\section{Discussion of Findings}

\subsection{Cognitive, Social and Emotional Development of Children}

It has been noted from this study that single parenting has an effect on the cognitive, social and emotional development of children. Earlier studies also report similar findings. For instance, studies by Azuka-Obieke, 2013; Salami and Alawonde (2002); Roska and Potter (2011) report that children from divorced families and from single parenting households were likely to have academic problems. They also found out that single parents have less time for their children that severely impact how those children performed at school. The current study has indicated that children living 
with their mothers, aunts and grandmothers were more likely to report their parents being able to attend school meetings than those living with their fathers. Children with their fathers were less likely to report good grades while those living with paternal aunts and maternal grandmothers were also more likely than those living with maternal uncles to report getting good grades at school. According to Moime (2009) children basically perform better at school when parents are involved and those children whose parents help them at home, and remain in close contact with their school, score much higher than children whose parents are not involved.

Findings have also shown that older children (especially the 20 and 22 year olds) were more positive than the 1215 year olds in suggesting that their situation at home had an effect on their school performance. This may be due to the fact that children between 12-15 years old are preoccupied with discovering themselves so did not take much interest in what was happening at home as compared to the 20 and 22 year olds. However, this appears to be in line with what Erikson advocates in his theory of development that children who are between 12-17years explore possibilities and begin to look for their identities based upon the outcomes of their explorations. Erikson emphasizes that as children get older, they are confronted with many new roles and adult statuses, so the parents need to allow the children to explore many different roles and different paths within a particular role (Bandura, 1977; Ajidahun, 2011; Falana et al., 2012). If the adolescent according to Scott and Lilja (2010) explores such roles in a healthy manner and arrives at a positive path to follow in life, then a positive identity will be achieved. The 14-16 year olds were also more likely to talk about their situation than the 22 year olds, which suggests that as children grow older they tend to keep issues to themselves, or they may well select who they speak to about certain issues.

Children living with their mothers were more likely than those living with their paternal uncles (generally males) to report missing the other parent and they were also more likely to report feelings of hatred. The paternal uncle may therefore make up for the missing father and these children were, as shown previously, males who may wish to identify with their paternal family. Living with a mother seems to develop more positive emotions; hence such children are less likely to report hatred for the other parent, when compared with those living with their father, grandparents, and aunts. Children living with their mother were also less likely than those living with their father to be afraid of losing their only parent or uncles. This could be linked with the feelings of hatred reported above. Scott and Lilja (2010) observed that children did better living with a single mother than they did with a father who was married to a stepmother. Children living with their mothers have shown to be generally females, and they were stronger in their responses than those living with their fathers, uncles and aunts with regards to their fears of losing their only parent. This then suggests that these females form very strong relationships with their mothers by living together.

Quantitative and qualitative data in the present study indicate that the female participants were emotional in comparison to the males. This accounted for why they sometimes felt like crying even when there was no clear reason to, but the males suggested otherwise. The responses also suggested that although both males and females were negative in their responses regarding to feeling of loss; the females were slightly inclined to admitting to feeling lost because they didn't have both parents, with a more negative response from the males. The female participants in the study further reported that they shared their feelings with others, which were not the case with the males. The information gathered points towards females being more emotional than the males. Quantitative data specifically revealed that the number of a child's siblings invariably has effect on the social development of the child. Children who did not have siblings were more likely to show feeling of happiness and this may be due to the fact that they were getting all attention from the only parent.

The findings revealed that there were children who did not know the other parent so they felt no gap in their lives especially because the parents had decent jobs and they were able to cater for the children's basic needs. Some of the adaptation strategies mentioned by the children involved lowering the standards of their expectations. The children pointed out that knowing that they could not get everything they wanted like other children, encouraged them to be responsible and ambitious so they had to work extra hard at school so that they could have a brighter future. The children also mentioned that they wanted to make their single parents proud and prove to the world and to their irresponsible parent that they could be responsible citizens even though he/she (missing parent) deserted them. The findings show that some of the respondents wanted to be like their single mothers because they were kind and responsible. This is in line with the findings by Doherty and Beaton (2004) who advocate that single parenting has positive effects on the child, pointing out that it is not all about being a single parent but it is all about parenting styles and close family ties between the parent and the children.

\subsection{Parent-child relationship}

According to Kelly (2003) communication is vital and should always be a two way synergy. Parents should listen to their children and find out what is going on in their lives. Children should also know that they can talk to their parents about 
anything under the sun. The children's descriptions of their relationships with their parents were varied. Many children living with their mothers mentioned that they had negative emotions towards their fathers they were not living with, who either abandoned them or were not taking care of them. The findings show that some children did not have good relationships with their parents. Many respondents held fond emotions for the "loving and caring" father who died while they were still young. The findings revealed accounts of children reporting loving, close and trusting relationships with their mothers; this was mentioned by children regardless of their gender. Those who reported negative emotions towards their mothers cited the mothers being involved in other relationships so the mother was either ill-treating the children because of the new found love or was mishandling the estate left by their late father.

From the focus group discussion it emerged that most parents did not have quality time with their children as a result they did not know exactly what was going on in their children's lives. Some children mentioned that they had developed hatred towards their irresponsible parents. This was bound to have negative effects on the psychosocial development of the children. Moime (2009) emphasizes that the family is a training ground for having relationships. If a child has failed to have a sound relationship with the parent it was most likely that the child would never have any sound relationship with anyone. According to Jaffe (1994) the relationship between parent and child should be warm, inviting and interesting. Children need to have responsive parents to whom they are securely attached. Even when a parent is single it does not change the role he/she has to play as a parent. The single parents too have to extend parental sentiments and support to their children. One of the challenges of parenting is teaching children to get along with each other (Kelly, 2003).

The findings revealed that some children do not have good relationships with their siblings due to the situation at home. Since some children stayed in one single parented household they did not have good relationships as siblings. This was caused by the fact that they were many children and they were of different surnames thus causing the mother to have favourites amongst the children. The children who were not favourites mentioned that this affected their self-esteem. The self-esteem is concerned with how one evaluates and feel about oneself. Cavanagh and Fomby (2012) point out that people who like and accept themselves tend to have more satisfying and productive lives and better relationships. The ability to accept and like ourselves is rooted in the feedback we get from other people early in our lives (Moime, 2009). The parents or caregivers are the ones responsible for building and reinforcing a positive self-esteem amongst the children which eventually helps in the psychosocial development of the children. It becomes difficult for the single parent to build and reinforce a positive self-esteem amongst the children when in fact the parent himself or herself is struggling with own self esteem.

\section{Conclusions}

It is clear that single parenting is not an easy task as this study has shown. The results of this study have shown that it is not easy to raise children as a single parent since one has to deal with multiple issues all alone. As a result, it is important for individuals to be aware of the consequences of the parenting type they intend to go into on themselves and on their children. The researchers therefore conclude that although single parenting type may have some good benefits for the child, however, our findings would suggest that the negative sides to it appear to cancel out those positive outcomes.

\section{Limitations of the Study}

The researchers felt the importance of pointing out some of the limitations of this study. The researchers would have loved to get views from primary school going children but due to time constraints they were unable to get their views. The researchers were also aware that Swaziland has four geographic regions and there were schools and children located in all four regions. Due to time and financial constraints, it was difficult to get views from children and parents from all regions hence only Manzini and Shiselweni regions were chosen. This narrowed the chances of generalizations on the effects of single parenting on the psychosocial development of children in Swaziland.

\section{Recommendations}

Based on the findings of the study it would be plausible to suggest that single parents need some counseling that may better position them to help their children develop psychosocially. On the part of the teachers, it is recommended that teachers undertake to understand diversities in contemporary families. Knowing these children will help especially the guidance and class teachers' deal with the children better with an understanding of the exact situation at home. Teachers must be aware that since the children spend the better part of their life at school, the school then becomes second 
important environment for the psychosocial development of the children. Teachers therefore need to be properly trained and equipped to deal with issues relating to the kind discussed in this study. There is also the need for specific policy that compels all parents to take responsibility of their children.

\section{References}

Ajidahun, B. O. (2011). Impact of psychosocial factors on the adolescents' behaviour. Creative Education, 2(4): 398-401.

Amato, P. R., Kane, J. B., James, S. (2011). Reconsidering the good divorce. Family Relations, 60(12): 511-524.

Azuka-Obieke, U. (2013). Single-parenting, psychological wellbeing and academic performance of adolescents in Lagos Nigeria. Journal of Emerging Trends in Educational Research and Social Studies, 4(1): 112-117.

Babbie, E. R., \& Mouton, J. (2001). The practice of social research. Cape Town: Oxford University Press Southern Africa.

Bandura, A. (1977). Social learning theory. New York: General Learning Press.

Bosma, H. A., \& Kunnen, E. S. (2001). Identity and emotion. New York: Cambridge University Press.

Cavanagh, E. S., \& Fomby, P. (2012). Family instability, school context and the academic careers of adolescents. Journal of Sociology in Education, 85(1): 81-97.

Cohen L., Manion, L., \& Morrison, K. (2005). Research methods in education (5th Ed). New York: Routledge Falmer.

Copeland, D. B. (2010). Psychological differences related to parenting infants among single and married mothers. Issues in Comprehensive Pediatric Nursing, 33: 129-148.

Creswell, J. W. (2014). Research Design: Qualitative, Quantitative and Mixed Approaches. (4th Edition). Thousand Oaks; California: Sage.

Crosnoe, R. (2007). The connection between academic failure and adolescent drinking in secondary school. Austin, USA: University of Texas at Austin.

Davidson, J. (2000). Giftedness. Encyclopedia of psychology. New York: Jacksonville State University.

Davis, K. E. (2011). Review of Children of divorce: stories of loss and growth. Columbia: Tyler and Francis.

Doherty, W. J., \& Beaton, J. M. (2004). Mother and fathers parenting Together. New Jersey: Erlbaum.

Falana, B. A., Bada, F. O., \& Ayodele, C. J. (2012). Single-parent family structure, psychological, social and cognitive development of children in Ekiti State. Journal of Educational and Developmental Psychology, 2(2): 158-164.

Good, T. L., \& Brophy, J. (1995). Contemporary educational psychology. New York: Longman Publishers.

Guest, A.M. (2007). Taking studies, lifespan development. New York: McGraw-Hill.

Heffner, C. (2004). Erickson's stages of psychological development. Retrieved 22 April, 2014 from: http://allpsy.con/psycology 101/social development.html

Jaffe, M. L. (1994). Understanding parenting. Washington, DC: Brown Publishers.

Kaseke, E., \& Gumbu, P. (2001). The aids crisis and orphan care in Zimbabwe. Social Work, 37(1): 53-58.

Kelly, B. (2003). If you are a parent, you are a role model. Clearing House, 81: 117-121.

Leedy, P. D., \& Ormrod, J. E. (2010). Practical research (9thed.). New Jersey: Pearson Education Inc.

Merriam, S. B. (2002). Qualitative research and case Study Approach in education. San Francisco: Jossey-Bass.

Moime, W. M. (2009). The effect of orphanhood on the psychological development of pre-primary and primary school learners. Unpublished Doctoral thesis. Pretoria: University of South Africa.

Mwamwenda, T. S. (2004). Educational psychology: An African perspective. Pretoria: Heinemann.

Naug, K. (2000). Maternal social network in an urban slum and its impact on cognitive and social development in children. Journal of Personality and Clinical Studies, 16(1): 53-62.

Neumann, W. L. (2006). Social Research Methods: Qualitative and Quantitative Approach (6 $6^{\text {th }}$ Ed) Allyn and Bacon. Boston.

Nyakutse, G. (2006). Communicating with children in crisis. Paper presented at the $8^{\text {th }}$ network conference for preschool teacher training and development in Southern Africa held April, $22^{\text {nd }}-28^{\text {th }}$ in Manzini Swaziland.

O'Connor, T. G., \& Scott, S. B. C. (2007). Parenting and outcomes for children. York, United Kingdom: Joseph Rowntree Foundation.

Pharaoh, R. (2004). A generation at Risk? HIV vulnerable and security in South Africa. Pretoria: Institute for Security Studies.

Roska, J., \& Potter, D. (2011). Parenting and academic achievement: Intergenerational transmission of educational advantage. Journal of Sociology in Education, 84: 299-318.

Salami, S., \& Alawode, E. (2000). Influence of single parenting on the academic achievement of adolescents in secondary schools: Implications for counselling. Ilorin Journal of Education, 20: 1-8.

Santrock, J.W. (2006). Life span development. Contemporary learning series. USA: McGraw- Hill.

Schumacher, S., \& McMillan, J. (2006). Research in Education in Education: Evidence-based inquiry (6th Ed). Boston: Pearson Education.

Scott, M. E., \& Lilja, E. (2010). Single custodial fathers' involvement and parenting: Implications for outcomes in emerging adulthood. Journal of Marriage and Family, 72(10): 1107-1127.

Simons-Murton, B., Haynie, D.L., Crump, A.D. Saylor, K.E. (2001). Peer and parent influences on smoking and drinking among early adolescent. Health Education and Behavior, 28(1): 95-107.

Steinberg, L. D., \& Silk, J. S. (2002). Parenting adolescents: Handbook of parenting (2nd.ed.). New Jersey: Erlbaum.

Stevenson, H. W., \& Zusho, A. (2002). Adolescence in China and Japan: Adapting to changing environment. New York: Cambridge.

Strauss, R. S. (2001). Environmental tobacco smoke and serum vitamin C levels in children. Pediatrics, 107(3): 540-542. 
Symeon, L. (2007). Cultural capital and family involving in children's education: Tales from primary schools in Cyprus. British Journal of Sociology in Education, 28(4): 473-487.

Thwala, S. (2011). The psychosocial world of orphans and vulnerable children: The implications of psychosocial support for orphans and vulnerable children in Swaziland. Germany: VDM Verlag Dr. 